\title{
Exciting new developments at The Bulletin
}

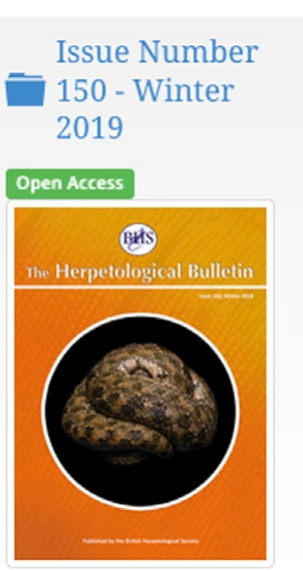

T

he Bulletin is moving with the times and there are several changes in this issue. From now on, the PDF of the full issue of The Bulletin will have its table of contents hyperlinked to the articles. This makes all articles just a click away. And for ease of access, this table of contents has been moved to the front inside cover although it will remain on the back cover of The Bulletin hardcopy.

There is another electronic development. The BHS has now established its own video channel on YouTube that you can see here. The Bulletin encourages authors to enliven their articles by linking them to informative video footage. Articles with such links are open access from the time of publication (other articles are embargoed for a year). All 'Bulletin videos' are posted on the BHS video channel, so you can easily browse the full video collection to find ones of interest. Should you wish to delve deeper into the subject then just click the link provided in the accompanying introductory text to go to the original article on the BHS website.

For those who receive the hardcopy of The Bulletin there is a further development. From this issue onwards, The Bulletin will be printed in full colour (the PDF on the website has always been in full colour). No more black and white images of your favourite species or maps and figure where colour would have made them much more interesting. Finally, for those who like to dig back into the archives, all

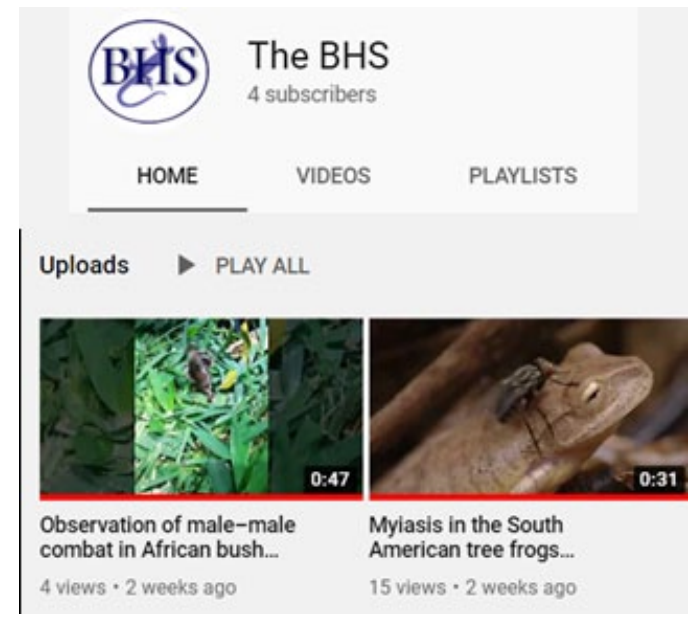

Check out the new BHS video channel that houses videos linked to Bulletin articles. You can browse the videos and then, by following hyperlinks, see the original articles. These articles are open access from the time of publication. back issues of The Bulletin are now available on the BHS website, all the way back to Issue 1 in 1980. Apart from the four most recent issues (which are members-only for the first year), these are all open access.

In this issue of The Bulletin we kick off 2021 with a cracking range of 20 articles; there has been no shortage of submissions to choose from (see The Bulletin Report in this issue). Four of the articles connect to video footage - the breeding biology of Indirana cf. tysoni from India, the invasive Johnson's whistling frog from Colombia, observations on behaviour akin to parental care in a slow worm, and male combat in a kukri snake from Thailand. There are also articles on a frog eating spider, the oldest captive Madeira rock lizard, and observation in Dorset of aggressive behaviour between the exotic wall lizard and native sand lizard. And to top all that, there is a review of the world's most comprehensive book on lizards.

Rick Hodges

Scientific Editor 